\title{
Nanoteknologia: artsenikoaren erauzketarako bide berria
}

\author{
Itziar Galarreta, Iñigo Lozano eta Idoia Ruiz de Larramendi* \\ Kimika Ezorganikoa Saila, Farmazia Fakultatea (UPV/EHU) \\ *idoia.ruizdelarramendi@ehu.eus
}

DOI: $10.1387 /$ ekaia.14572

Laburpena: Artseniko peko egonaldiak osasunerako eta sistema ekologikoetarako oso kaltegarriak dira, kontzentrazio txikietan izanda ere. Hori dela eta, egungo ingurumen-ikerlari askoren erronka da artsenikoa modu eraginkorrean erauzteko metodo berri bat aurkitzea. Gaur egun, disoluzioan dagoen artsenikoa erauzteko metodo asko daude: prezipitazioa, oxidazioa, mintz bidezko prozesuak, gainazaleko konplexazioa, adsortzio selektiboa,... Adsorbatzaile nanometrikoak, dituzten propietate kimiko eta fisikoei esker, ingurumen-berreskurapenerako materialik egokienak dira. Lan honek helburu modura hartu du artsenikoz kutsatutako uren tratamenduan erabiltzen diren nanoadsorbatzileei buruzko ezagutza eskaintzea du helburu, nanoteknologia arloko ikerkuntzaren etorkizunaren inguruko ikuspegi berri bat emanez.

Hitz-gakoak: artsenikoa, nanoteknologia, nanoadsorbatzaileak.

\begin{abstract}
Exposure to arsenic (As), even at trace level, is believed to be a risk for human health and ecological systems. Thus, how to effectively and deeply remove arsenic from water systems is a very important but still challenging task for environmental researchers. A great variety of water treatment methodologies such as precipitation, oxidation, membrane processes, surface complexation or selective adsorption have been studied for significant reduction or remove arsenic from contaminated effluents. The use of nanomaterials as adsorbent materials for environmental remediation has a great potential due to their physical and chemical properties. This work aims to provide greater depth of understand of the successful integration of nanoadsorbents in water treatment technologies and give new insights into future research directions for the implementation of the nanotechnologies in a near future.
\end{abstract}

Keywords: arsenic, nanotechnology, nanoadsorbents. 


\section{SARRERA}

Artsenikoak historian zehar erabilpen ugari izan ditu, eta besteak beste, pozoirik ezagunena izan da. Horren adibide gisa esan daiteke Lehenen Mundu Gerran eta Vietnamgo Gerran erabilitako arma biologikoek artsenikoa zutela. Kasuak kasu, Napoleon Bonaparterena da istoriorik ospetsuena. Urteetan zehar sabel-minbizi batek heriotza ekarri ziola uste izan bada ere, honen ilean aurkitutako artseniko kontzentrazio altuak pozoinduta hil zela erakutsi zuen.

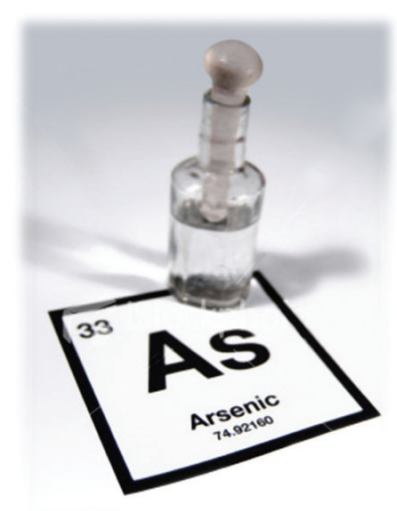

1. irudia. Artsenikoa.

Gaur egungo erabilerak oso desberdinak eta urriak dira, batik bat bere izaera toxikoagatik. Nagusiki, honetarako erabiltzen da:

- Kotxe-baterietan erabiltzen diren kobre-berun $(\mathrm{Cu}-\mathrm{Pb})$ aleazioak indartzeko.

$-n$ motako gailu erdieroale elektrikoak dopatzeko.

- Koloratzaileak eta beira optikoa egiteko.

- Sifiliaren kontrako sendagai eraginkorra denez, antibiotiko gisa abereen pentsua ongarritzeko.

- Medikuntza munduan ${ }^{74} \mathrm{As}$ isotopoa minbizia tratatzeko eta tumoreak detektatzeko.

- Onddo, bakterio eta intsektuekiko duen erresistentzia dela eta, herbizidak $\left[\mathrm{Na}_{3} \mathrm{AsO}_{3}\right]$, pestizidak $\left[\mathrm{Pb}_{3}\left(\mathrm{AsO}_{4}\right)_{2}\right.$ eta $\left.\mathrm{Ca}_{3}\left(\mathrm{AsO}_{4}\right)_{2}\right]$, intsektizidak eta egurra mantentzeko produktuak egiteko.

Aipatu berri diren herbizidak, pestizidak eta intsektizidak, euren funtzioetan oso eraginkorrak badira ere, artseniko-kutsadura antropogenikoa- 
Nanoteknologia: artsenikoaren erauzketarako bide berria

ren arduradun nagusiak dira. Hauen erabileraren ondorioz, tratatutako produktuak (batez ere uztak) kutsatu eta lurzoruan pilatzen dira [1-2].

Artsenikoa lurrazalean, airean eta uretan ager daiteke [2]. Metaloide edo erdimetal moduan sailkatuta dago eta metal eta ezmetalen arteko propietate kimikoak ditu. Lehenengo irudian ikus daitekeen bezala, kolore gris metalikoa du eta bere pisu atomikoa $74,9216 \mathrm{~m}$. a. u. da. Ingurumenean lau oxidazio egoeratan aurki daiteke: artseniko elementala [As(0)], artsanoa [As(-III)], artsenitoa [As(III)] eta artseniatoa $[\mathrm{As}(\mathrm{V})]$. Naturan ohikoenak artsenitoak eta artseniatoak dira [3]. Hori dela eta, artseniko elementala eta artsanoa alde batera utziko ditugu, beste biei arreta osoa eskaintzeko.

As(III) konposatuek elektroi pare bat partekatzen ez duten deribatu piramidalak osatzen dituzte. Horren ondorioz, Lewisen azidoekin eta trantsizio metalekin konposatuak eratzen dituzte. $\mathrm{As}(\mathrm{V})$ konposatuak aldiz, egitura trigonal bipiramidalak eratzen ditu eta ez du elektroirik partekatzen; hori dela eta, egonkorra da naturan [4].

Naturan, leherketa bolkaniko, itsas aerosol edo askapen biogenikoen bidez iristen da artsenikoa atmosferara. Bertan esekiduran dauden partikuletan adsorbatzen da eta ordu edo egun batzuen ostean, uretan edo lurzoruan sedimentatzen da [2]. Normalean, kontzentrazio txikietan aurkitzen da ingurumenean, baina munduko hainbat eremutan artseniko ezorganiko kontzentrazio oso altuak ageri dira. Zoritxarrez, horren adibide nagusiak Argentina, Txile, Txina, India eta Mexiko dira [3]. Honek bertako biztanleria arriskuan jartzen du. Izan ere, artseniko ezorganikoaren kontsumoak giza osasuna arriskuan jartzen du epe luzera.

Gaitz hau ikusita, asko izan dira honi konponbide bat ematen saiatu direnak. Artikulu honetan artsenikoaren gaur egungo egoeraren berri emango da eta bere erauzketarako metodologiak aurkeztuko dira.

\section{ARTSENIKOA INGURUMENEAN}

Artsenikoa lurrazaleko 200 mineral baino gehiagoren osagaia da: alde batetik, mineralen egitura kristalinoaren parte izan daiteke; bestetik, mineralen osagaietako batek adsorbitua ager daiteke. Mineral hauek zein artseniko ezorganikodun bestelako espezieak bost talde desberdinetan sailka daitezke: artseniko elementala, artseniuroak, artsenosulfuroak, artsenitoak eta artseniatoak [5]. Kasu honetan, beren izaera toxikoa dela eta, artseniatoak sakonago aztertuko dira.

Artseniatoak (agardita, escorodita, uranospinita...) arku kontinentaletako subdukzio-gune magmatikoekin harremanetan daude. Ingurune hauetan urtutako arrokaz osatutako silizedun disoluzio urtsuak, gasak, katioietan aberatsak diren urak eta mineralak daude. Antza denez, eremu hauetan 
dauden baldintzen (presio eta tenperatura) eta osagaien (gasak, katioiak, mineralak...) eraginez, artsenikoan aberatsak diren lur barneko ur hidrotermalak eta mineralizazio guneak sortzen dira [5]. Kasu askotan eratzen diren mineralak, interes ekonomikokoak dira eta meategietan lantzen dira gerora. Haien ustiaketak bertako ingurunea eta langileak kaltetzen ditu, metal preziatuen eskurapen prozesuan artseniko kopuru handiak askatzen baitira.

Era berean, subdukzio guneetan dauden katioietan aberatsak diren ur hidrotermalek, lur barneko presio eta tenperatura aldaketen ondorioz, lurrazalean gora egingo dute, bidean topatzen dituzten beste elementuekin mineral berriak sortuz. Halaber, ur hauek gora egiten duten heinean, lur azpiko urekin nahasiko dira. Gainera, inguru magmatikoa izanik, gune hauetan gertatzen diren leherketa bolkanikoetan kanporatzen diren arroka estrusiboetan eta errautsetan ere artsenikoa agertuko da. Errauts hauek atmosferara isuri ostean aire korronteen bidez garraiatuko dira, ibai, aintzira edo itsasoa bezalako eremu hezeetan zein lehorretan (lurzorua) sedimentatu arte [6].

Lurzoruan, 2. irudian ikusten den bezala, bertan bizi diren mikroorganismoengatik xurgatua izan daiteke. Hauek artsenikoa erreduzituko dute eta atmosferara itzuliko dute. Mikroorganismoengatik bereganatuta izan ez den artsenikoak konposatu berriak sortuko ditu lurzoruan ioi moduan dauden beste espezieekin. Oro har, aluminio, magnesio eta burdina duten lurzoruetan, izaera limotsua eta buztintsua dutenak, artseniko kontzentrazio altuagoak agertzen dira [3]. Sortutako espezie berri hauek zein aske dagoen

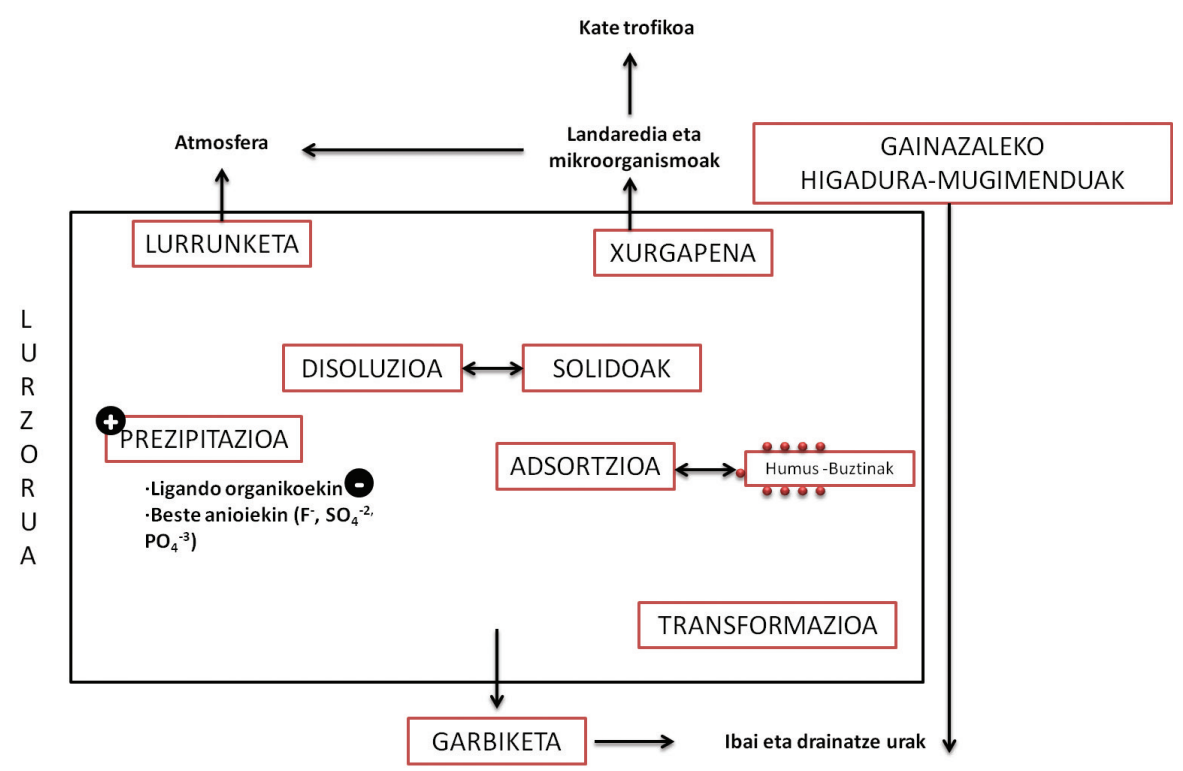

2. irudia. Artsenikoak lurzoruan jasaten dituen eraldaketa prozesuak. 
Nanoteknologia: artsenikoaren erauzketarako bide berria

artsenikoa euri azidoen bidez lur azpiko uretara lixibatu eta lur azpiko urekin nahas daitezke.

Uretan sedimentatuz gero, amaiera anitz izan ditzake. Uretan normalean artseniko ezorganikoa $\left(\mathrm{As}^{+3}\right.$ zein $\left.\mathrm{As}^{+5}\right)$ agertzen da eta uren $\mathrm{pH}$ eta osagaiek (oxidoak, hidroxidoak, karbonatoak...) baldintzatuko dute bere amaiera. Uretan, lurzoruan bezala, beste metalen presentziak espezie berrien sorrera eragingo du. Espezie horiek prezipitatu daitezke ibai, erreka, itsaso zein aintziren hondoan. Sufrean aberatsak diren eremuetan konposatu disolbaezinak era daitezke, $\mathrm{pH}$ neutro-azidoetan erraz mugitzen direnak.

Hortaz aparte, uretan bizi diren bizidunek artsenikoa barneratu dezakete arnasketa zein elikatze prozesuen bidez: adibidez algek artsenikoa ehunetan pilatzen dute, baina arrainek, gizakiok bezala, artsenikoaren metilazioa bideratzen dute. Prozesu hau artsenikoa organismotik sekrezio bidez kanporatu ahal izateko egiten da, baina osorik kanporatzea oso zaila denez, gorputzean ere pilatuta geratzen da. Mikroorganismoek ere, aurreko kasuan bezala, xurgatu ahal dute, eta ondorioz espezie berriak eratu [3].

Gizakia ingurumenetik at irudikatzen da askotan, baina gizarte askotan, harreman zuzena du lehen aipatu diren ur, ibai, erreka edo itsasoko arrainekin eta urarekin. Garapen bidean dauden herrialdeetan, oso ohikoa da eguneroko bizitzan kutsatutako uren erabilera. Ondorengo atalean ikusiko dugu gaixotasun askoren eragile izan daitekeela erabilera hori.

\section{ARTSENIKOAREN TOXIZITATEA}

Hasieran esan bezala, artsenikoa toxikoa da, baina bere toxikotasuna oxidazio egoeraren eta disolbagarritasunaren araberakoa da. Artsenikoa, modu organikoan ( $\mathrm{C}$ edota $\mathrm{H}$-rekin lotuta) zein ezorganikoan $(\mathrm{O}, \mathrm{Cl}$ edo S-rekin lotuta) aurki daiteke, baina, orokorrean, bizidunentzat kaltegarriagoak dira artseniko ezorganikodun espezie kimikoak artseniko organikokoak baino. Gainera, $\mathrm{As}^{+3}$ duten espezieak $\mathrm{As}^{+5}$ dutenak baino kaltegarriagoak dira. Honek artsenikoaren metabolismoan eragina izanen du, baina eragin hori desberdina da espeziearen arabera [7].

Artsenikoaren metabolismoa espeziearen erredox-potentzialaren eta metilazioaren arabera gertatzen da. Orain arte, uste izan da animalia zein gizakietan artsenikoaren desintoxikazio prozesuaren parte dela artseniko ezorganikoaren metilazioa. Ikerketa batzuetan ikusi da ordea, toxikotasun handiagoa duten substantzien sortzaile dela, eta azido monometilartseniosoa (MMA $\left.{ }^{\mathrm{III}}\right)$ eta azido dimetilartseniosoa $\left(\mathrm{DMA}^{\mathrm{III}}\right)$ dira adibide nagusiak. Azido dimetilartsinikoa $\left(\mathrm{DMA}^{\mathrm{V}}\right)$ eta azido monometilartsinikoa $\left(\mathrm{MMA}^{\mathrm{V}}\right)$ organismotik gernu bidez kanporatzen dira metabolizatu gabeko artsenikoarekin batera $[5,7]$. 
Arnasketa bidezko kutsapena posiblea bada ere, azal zein beste bidezko kontaktua da artseniko kontaminazioaren iturri nagusia. Gehienetan ura eta jakiak dira gertaera hauen eragile nagusiak. Ura eguneroko bizitzan ezinbestekoa da eta gizakiok edateko erabiltzeaz gain, garbitzeko, dutxatzeko eta janaria prestatzeko erabiltzen dugu. Hortaz, artsenikoz kutsatutako ura helburu hauetarako erabiltzeari uzten ez bazaio, artsenikoak sortutako gaixotasunak ugariagoak dira [8].

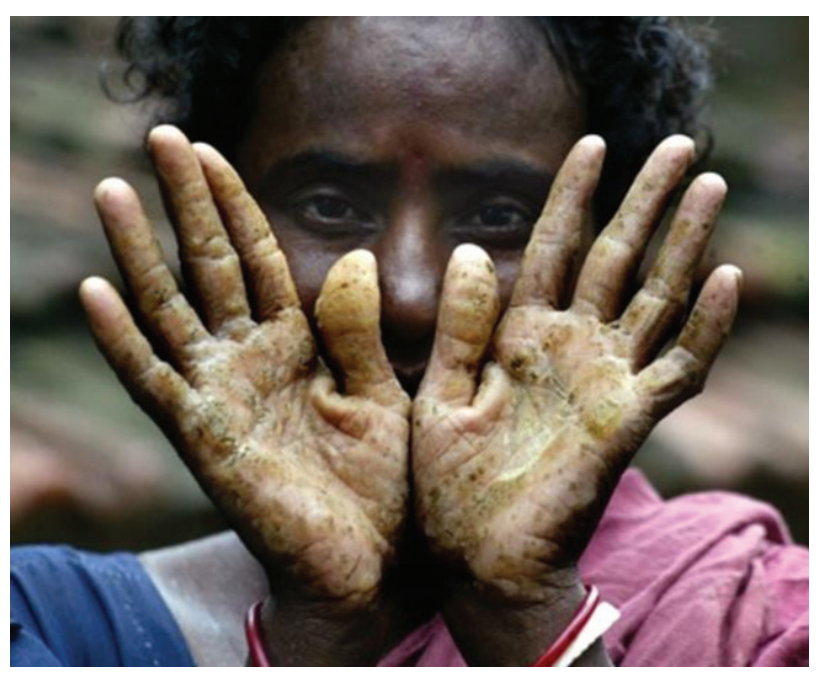

3. irudia. Artsenikoak eragindako azal-pigmentazioa [9].

Elementu kimiko honen $\mathrm{LD}_{50}$ ikertu da, artseniko kontzentrazio kaltegarria zein den zehazteko. LD siglek ingeleseko «lethal dose» esan nahi dute, hau da, dosi hilgarria. Horrela, $\mathrm{LD}_{50}$ animalia/giza talde baten \%50aren heriotza eragingo lukeen substantzia kimiko baten kontzentrazioaren adierazlea da. EPAren arabera, hauek dira bizidun desberdinetan taldearen \%50a ekarriko lukeen artsenikoaren dosi hilgarriak $\left(\mathrm{LD}_{50}\right): 15-293 \mathrm{mg} / \mathrm{kg}$ arratoientzat, $26-43 \mathrm{mg} / \mathrm{kg}$ saguentzat, $9 \mathrm{mg} / \mathrm{kg}$ Gineako txerrientzat eta $1-4 \mathrm{mg} / \mathrm{kg}-\mathrm{koa}$, gutxi gorabehera behera, gizakientzat. Metaloide honek bere lehenengo sintomak eta gaixotasunak eragiten ditu gizaki batek 1-4 mg hartzen baditu kilogramoko: neuropatia periferikoa, anemia, gibel eta giltzurrun-disfuntzioa, azal-pigmentazioa (ikusi 3. irudia), gaixotasun kardiobaskularrak eta diabetesa. Hainbat organotako minbiziekin batera, gaixotasun hauek dira artsenikoak gizartean agerian eragiten dituen kalte nagusiak [10]. Artsenikoaren kontsumoak eragiten dituen kalteak ikusita, Osasunerako Mundu Erakundeak $10 \mu \mathrm{g} / \mathrm{L}$-ko artseniko kontzentrazioa proposatu zuen ur edangarrirako gehienezko muga modura [11]. Horrela, murriztu egin nahi izan zuten artsenikoak eragindakoa gaixotasunen larritasuna. 
Nanoteknologia: artsenikoaren erauzketarako bide berria

\section{ARTSENIKOAREN ERREMEDIAZIOA}

Artsenikoak sor ditzakeen arazoak ikusita, asko izan dira gaitz honi konponbidea eman nahi izan diotenak. Kutsatutako urak tratatzeko metodo eraginkorra lortzeko bidean, energia eta kostu baxuko eta eraginkortasun altuko teknika lortu nahi dute; ingurumena kaltetuko ez duen teknika izan beharko da gainera. Gaur egungo gizarteak energia edo elektrizitatearekiko duen menpekotasuna harreman estuetan dago auzi honekin. Artikulu honetan, zazpi multzotan sailkatuta emango dira orain arte garatutako hainbat teknika: hauspeatze kimikoa, koagulazio-flokulazioa, flotazioa, mintz bidezko bereizketa, tratamendu elektrokimikoa, ioi-elkartrukea eta adsortzioa.

\subsection{Hauspeatze kimikoa}

Hauspeatzea prozesuan, hidroxidoak edo sulfuroak bezalako erreaktiboak erabiltzen dira suspentsioan dauden konposatu disolbagarriak konposatu solido disolbaezin bilakatzeko [12]. Horrela, disoluziotik erauzi nahi den konposatua hauspeakin bilakatzen da, eta filtrazio zein sedimentazio bidez erauzi daiteke soluziotik. Egun, prozesu ohikoenetarikoa da, oso bakuna delako eta eraginkortasun handia duelako solutu disolbaezinen kontzentrazio handietan [13]. \%80-90 inguruko eraginkortasuna du [14], baina kontzentrazio txikia duten hondakinak tratatzeko ez da eraginkorra. Gainera, erreaktiboen erabilerak eta uraren tratamendu osoa egiteko, prozesu osagarriak behar dira eta horrek garestitu egiten du metodoa; hori gutxi balitz, tratatzeko zailak diren hondakin-bolumen handiak sortzen ditu, eta horrela ingurumena kaltetua gerta daiteke.

\subsection{Koagulazio-flokulazioa}

Metodo honen bidez, soluzio batean suspentsioan dauden partikula koloidalak erauzten dira. Partikula koloidalek $10^{-6}-10^{-4} \mathrm{~mm}$ bitarteko tamaina dute; ez dute sedimentazio-joerarik aurkezten eta ez dira erauzten mintz bidezko filtrazio sistemen bidez [12]. Inguruan duten geruza elektriko bikoitza da partikula hauen berezitasun nagusia. Partikularen gainazalean dagoen gehiegizko kargak ioiek medio urtsuan duten banaketari eragiten dio. Horrela, partikulak karga positiboa badu, kontrako zeinua duten ioiak erakarriko ditu eta karga positiboa dutenak aldendu egiten ditu. Karga negatiboa izango balu, kontrakoa gertatuko litzateke. Geruza honek egonkortasuna ematen dio partikulari disoluzioan, eta ondorioz, zaildu egiten da partikularen erauzketa.

Honi aurre egiteko, partikula koloidalak dituen disoluzioari $\mathrm{Al}_{2}\left(\mathrm{SO}_{4}\right)_{3}$ edo $\mathrm{Fe}_{2}\left(\mathrm{SO}_{4}\right)_{3}$ bezalako koagulatzaileetako bat gehitzen zaio, eta ondorioz deuseztatu egiten da aipatu berri den geruza elektriko bikoitza. Honi esker 
partikula koloidalak batuz joango dira, mikroflokuloak (partikulaz eratutako nukleo mikroskopikoak) eratu arte. Ondoren, flokulatzaile bat gehitzen zaio (ikatz aktiboa eta poliakrilamida bezalako polimero sintetiko bat adibidez), sedimentadorearen hondoan flokulo handiak sortzeko. Honek erauzi nahi den substantziaren bakanketa erraztuko du. Hasierako disoluzioa bitan banatuko da: alde batetik kanporatu nahi den substantziaz osatutako flokuloak eratuko duten sedimentua eta bestetik ur zein disolbatzaile garbia [12].

Tratamendu erraza bada ere, hondakin bolumen handiak sortzen ditu eta aurrekoan bezala erreaktibo asko eta tratamendu osagarriak behar dira, erauzketa erabatekoa izan dadin. Bibliografiaren arabera [14] \%90-95eko eraginkortasuna du metodo honek eta hortaz, nahiko garestia da, baina eraginkorra.

\subsection{Flotazioa}

Kasu honetan aire-burbuilak erabiltzen dira, esekiduran dauden solutuak disolbatzailearen gainazalera eramateko. Modu honetan disoluzio azpiko aldetik airea sartu eta konposatuak burbuila barnean harrapatu eta gainazaleraino eramaten ditu; horrela, errazagoa gertatzen da konposatuen deuseztatzea [12]. Bolumen handiak tratatzeko aukera ematen du metodo honek. Gainera, bere hautakortasunak kontzentrazio handiko lohien ekoizpena ahalbidetzen du [13]. Baina, aurreko biak bezala, metodo garestia da, batik bat depositua eraikitzeko behar den diru kopuruarengatik, mantenu koste altuengatik eta eragiketaren kostuengatik.

\subsection{Mintz bidezko bereizketa prozesuak}

Talde honen barnean lau prozesu bereizten dira: Ultrairagazketa, $\mathrm{Na}$ noiragazketa, Alderantzizko Osmosia eta Elektrodialisia. Lauetan mintz batek parte hartzen du disoluzio batean dagoen solutu baten bakantze prozesuan. Ultrairazketan filtrazioan 150-250 $\mu \mathrm{m}$-ko lodiera duen eta 0,05-0,2 $\mu \mathrm{m}$ bitarteko poroa duen mintza erabiltzen da eta 1-10 bar bitarteko presiopean egiten da. Nanoirazketan filtrazioan aldiz, $150 \mu \mathrm{m}$-ko lodiera duen eta $0,002 \mu \mathrm{m}$ bitarteko poroa duen mintza erabiltzen da eta 5,35 bar-eko presio presiopean egiten da. Alderantzizko osmosian nanofiltrazioan erabiltzen den mintz mota bera erabiltzen da, baina 15-150 bar bitarteko presiopean egiten da. Amaitzeko, elektrodialisian substantzia ionikoen bidezko bereizketa egiten da, eremu elektriko baten eraginpean dagoen mintz hautakorrez osatutako sistema baten bidez [12].

Metodo guztiak oso konplexuak dira, baina eraginkortasun oso altua erakusten dute (\%95 ingurukoa). Edozein modutan, fluxu-abiadura moteletan lan egin beharrak erabili beharreko energia kopurua handitzen du, eta ondorioz metodoa oso garestia da. 
Nanoteknologia: artsenikoaren erauzketarako bide berria

\subsection{Elektrodeposizioa}

Metodo honek ahalbidetzen du metalak ioi moduan berreskuratzea. Oso prozesu bakuna erraza da: korronte elektrikoa eroaten duen likido baten barnean bi elektrodo, hau da katodo eta anodoa jartzen dira eta bi haien artean korronte elektrikoa eragiten da. Disoluzioan dauden ioi metalikoak erreduzitu egingo dira eta katodoaren gainazalean jarriko dira; horrela, metalaren berreskurapena bideratzen da [12]. Metodo honen eraginkortasuna, gertatutako korronte elektrikoaren araberakoa izanen da. Kontrolpean izateko metodo erraza eta azkarra da, baina ez du eraginkortasun oso handia. Gainera metodo garestia da, mantenu-ahalegin handiak, konposatu kimiko askoren erabilerak eta elektrizitatearekiko mendekotasunak direla eta.

\subsection{Ioi-elkartrukea}

Metodo honetan ere solido baten bidez berreskuratzen dira ioiak, baina ez da korronte elektrikorik behar. Ioiaren eta solidoaren arteko lotura kimikoak alderantzikagarriak dira eta adsortzioarenak baino ahulagoak. Ioielkartrukean disoluzio elektrolitiko batean dauden ioiak harrapatu eta antzeko karga duten beste batzuk askatzen dira, solidoaren barneko egitura solidoa aldatu gabe [12]. Erauzketa-gaitasun handiko teknika da, baina hondakin bolumen handiak era daitezke. Zoritxarrez, nahiko garestia da kontzentrazio altuko hondakin bolumenak tratatzeko. Sulfatoen eta nitratoen presentziak solidoen eraginkortasuna murriztu egiten du eta aurretik prebentzio-neurriak hartzea gomendatzen da, hots komenigarria da aurretratamenduak egitea. Honek tratamendua asko garestitzen du, askotan metodoa baztertzeko beste.

\subsection{Adsortzioa}

Esan bezala, disoluzioan dauden ioien erauzketa material solido baten bidez egiten da. Askotan ioiak zutabeen barnean kokatzen dira eta kutsatutako ura adsorbatzailetik igarotzean bertan atxikituta geratzen da erauzi nahi den substantzia [12]. Adsorbatzaile mota asko daude, baina hurrengoak goraipa daitezke: ikatz aktiboa, «low-cost» adsorbatzaileak, aktibatutako alumina, substratuak (area, lohiak, silizioa...), polimero organikoak, sustrai deshidratatuak, ur-hiazintoa eta burdin-konposatuak.

Ikatz aktiboak azken urteetan modan jarri den materiala da. Adsortzio gaitasun altua du eta berrerabilgarria den materiala da. Adsorbatzaile moduan erabili eta gero desortzio prozesu baten bidez ikatza garbitu (adsorbatutako espezieak erauzi) eta berriz adsorbatzaile moduan erabil daiteke. Kasu honetan artseniko kopuru oso txikiak erauzten ditu 
eta desortzio prozesuan zailtasunak aurkezten ditu. Gainera garestia da, metodoa kasu gehienetan baztertuta uzten duena. "Low cost» adsorbatzaileak (adibidez arroz-azalak) adsortzio-gaitasun nahiko txikia izaten dute. Alumina aktibatua eraginkorra da eta in situ berreraketa ahalbidetzen du, baina $\mathrm{pH}$ azidotan soilik da eraginkorra eta atsenikoaren aurreoxidazioa behar du (hiru balentziako artsenikotik bost balentzia duenera oxidatu egin behar da).

Oxidatu denean $\mathrm{As}(\mathrm{V}) \mathrm{AsO}_{4}^{-3}$ oxoanioi bezala egonkortzen da eta konposatu honen oxigeno atomoetan dagoen karga eraginkorra negatiboa da. Honi burdin oxidoak gehituz gero, disoluziotik As(V) oxoanioiak berreskuratuko dira. Hau, 4. irudian ikusten den bezala, oxidoaren gainazalean gertatzen den adsortzioari esker jazotzen da.

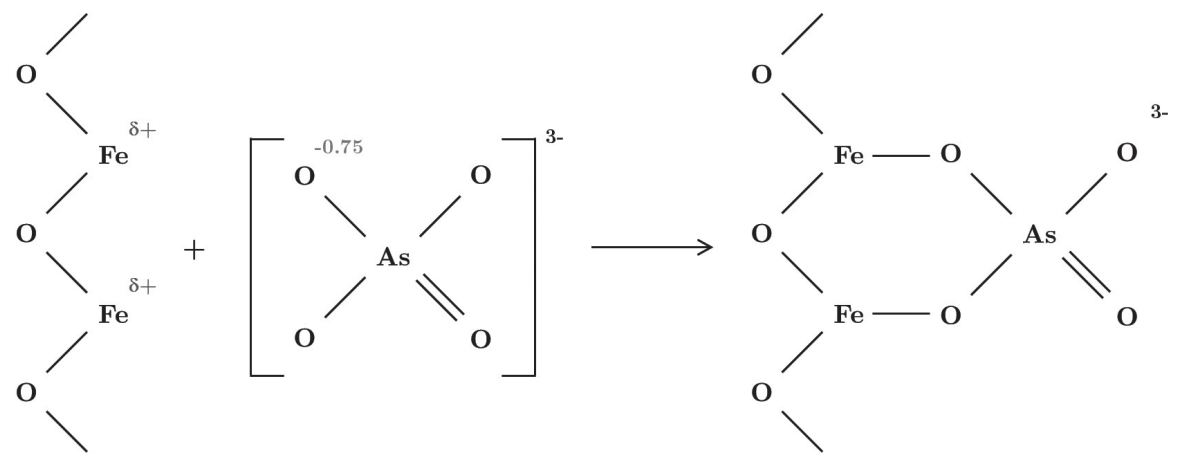

4. irudia. Burdin-oxidoen $\mathrm{As}(\mathrm{V})$-ren adsortzio prozesuaren eskema.

Substratuen metodoak onak dira, edonon eskuragarri daudelako substratuak, eta in situ berreraketa baimentzen dutelako. Baina alderdi txar bat dauka: eraginkortasun txikikoak dira eta beste kutsatzaile batzuen eraginez desaktibazioa pairatzen dute, eta horrek are gehiago murrizten du eraginkortasuna.

Polimero organikoek eraginkortasun altua dute eta gainera in situ berreraketa ahalbidetzen dute, baina disolbatutako solidoek eraginkortasuna mugatzen dute eta oso garestiak dira. Ur hiazintoa (Eichhornia crassipes) eta sustrai deshidratuak metodo nahiko berriak dira, eta horregatik optimizatu beharrean daude. Amaitzeko, burdin-oxidoek, hidroxidoek, oxihidroxidoek eta burdinaren forma amorfoek eraginkortasun oso altua erakutsi dute, \%95 ingurukoa. Gainera, beste adsorbatzaileak baino eskuragarritasun merkeagokoak dira. Artsenitoak oxidatzen dituzte eta haiek dira merkatuan dauden adsorbatzaile nagusien osagai garrantzitsuenak. Alde txarra aipatzearren, esan beharrekoa da ez direla berreraikitzen eta $\mathrm{pH}$ baxuetan baizik ez direla eraginkorragoak [15]. 
Nanoteknologia: artsenikoaren erauzketarako bide berria

\section{NANOTEKNOLOGIAREN ZEREGINA ARTSENIKOAREN ERAUZKETAN}

Esan bezala, beste teknika batzuetan baino diseinu malguagoa eta funtzionamendu egokiagoa lor daiteke adsorbatzaileak erabiliz. Aldi berean, erabiltzen diren adsorbatzaile gehienak desortzio prozesuen bidez berrera daitezke, eta horrela aukera egoten da adsorbatzaile bera hainbat ziklotan berrerabiltzeko. Aukera hauek ikusita, azken urteetan teknika hau asko garatu da ur kutsatuetatik artsenikoa bezalako metal astunen berreskurapenean. Badirudi sortu berri diren material adsorbatzaileen artean nanoteknologiarekin eta nanomaterialen diseinuarekin erlazio zuzena dutenak izango direla etorkizun oparoena izango dutenak.

Nanomaterialak nanometro $\left(10^{-9} \mathrm{~m}\right)$ neurriko partikulak dituzten sistemak dira. Nanoteknologiaren inguruko definizio asko egin dira, baina batek ere ez du bere osotasunean zientzia hau azaltzen. Hortaz, hurbilketa bat egitearren, esan daiteke zientzia honek (Nanoteknologia) nanoegitura eta nanomaterialen diseinu, fabrikatze eta aplikazioa jorratzen duela. Eskala horretan kokatzen diren material zein egiturak aztertzeaz gain, materialen propietate fisikoak eta dimentsioak uztartzen ditu. Gaur egun, biologo, kimikari, fisikari eta ingeniari asko izan dira material hauen aplikazioan interesa agertu dutenak. Haien ustez, hurrengo industria-iraultzaren pizgarri nagusiak izan daitezke [16]. Interes berezi honen eragile nagusiak material hauen ezohiko propietateak dira [17-19]. Sistema nanoegituratuen ezaugarrien eragile nagusiak hauek dira:

i. Partikulen dimentsioa fenomeno batzuen luzera kritikoaren antzekoa edo txikiagoa da; adibidez, De Broglieren elektroi uhin-luzera, Frank-Reed dislokazioa sortzeko behar den distantzia, elektroiaren batezbesteko bide askea, domeinu magnetikoaren tamaina...

ii. Nanomaterialek duten tamaina txikiak gainazal/bolumen erlazio handipena eragiten du eta propietate termodinamikoekin lotutako parametroak baldintzatuko ditu: egitura kristalinoa, erreaktibotasuna, imanazioa...

Lehenengo gertaerak material nanoegituratuen eta material azpieroaleen propietate elektriko, optiko eta magnetikoak azaltzen ditu; bigarrenak nanokristalek izan ditzaketen morfologia desberdinak [20-21] eta ekintza katalitikoak dituen aldaketak azaltzen ditu [22-23]. Gainazal/bolumen erlazioaren handipenaren ondorioz sortutako katalisi-gaitasunaren aldakortasun honek eraginkorragoak diren nanoadsorbatzaile berrien garapena ahalbidetzen du. Eraginkortasun-handipen hau ekintza katalitiko handiagoa duen gainazal espezifikoaren handipenari esker gertatzen da nagusiki. Erabilgarriak izan daitezkeen adsorbatzaileen artean hauek dira ur kutsatuaren tratamenduan ohikoenak: nanometrikoak diren oxido metalikoak - NOM. 


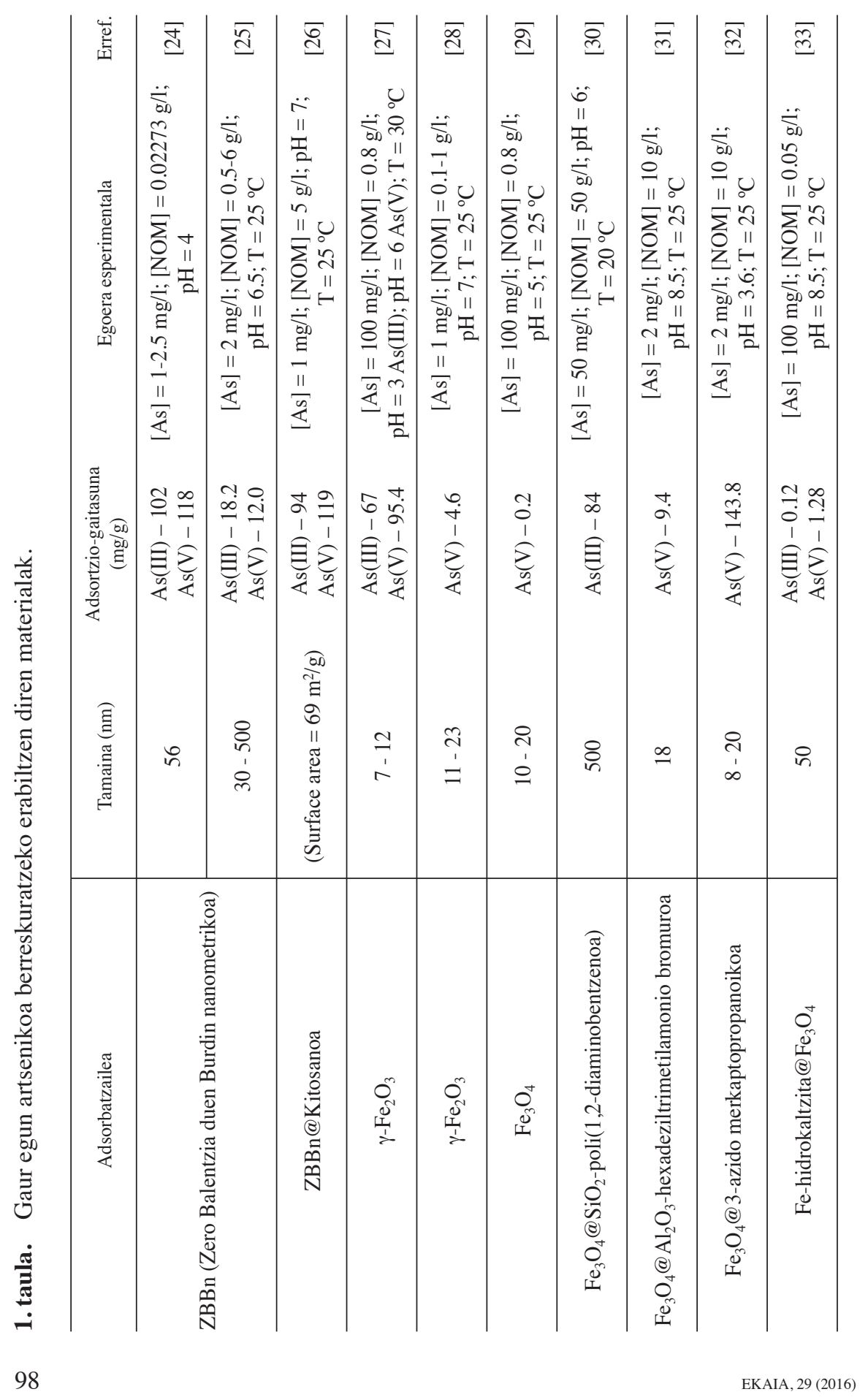




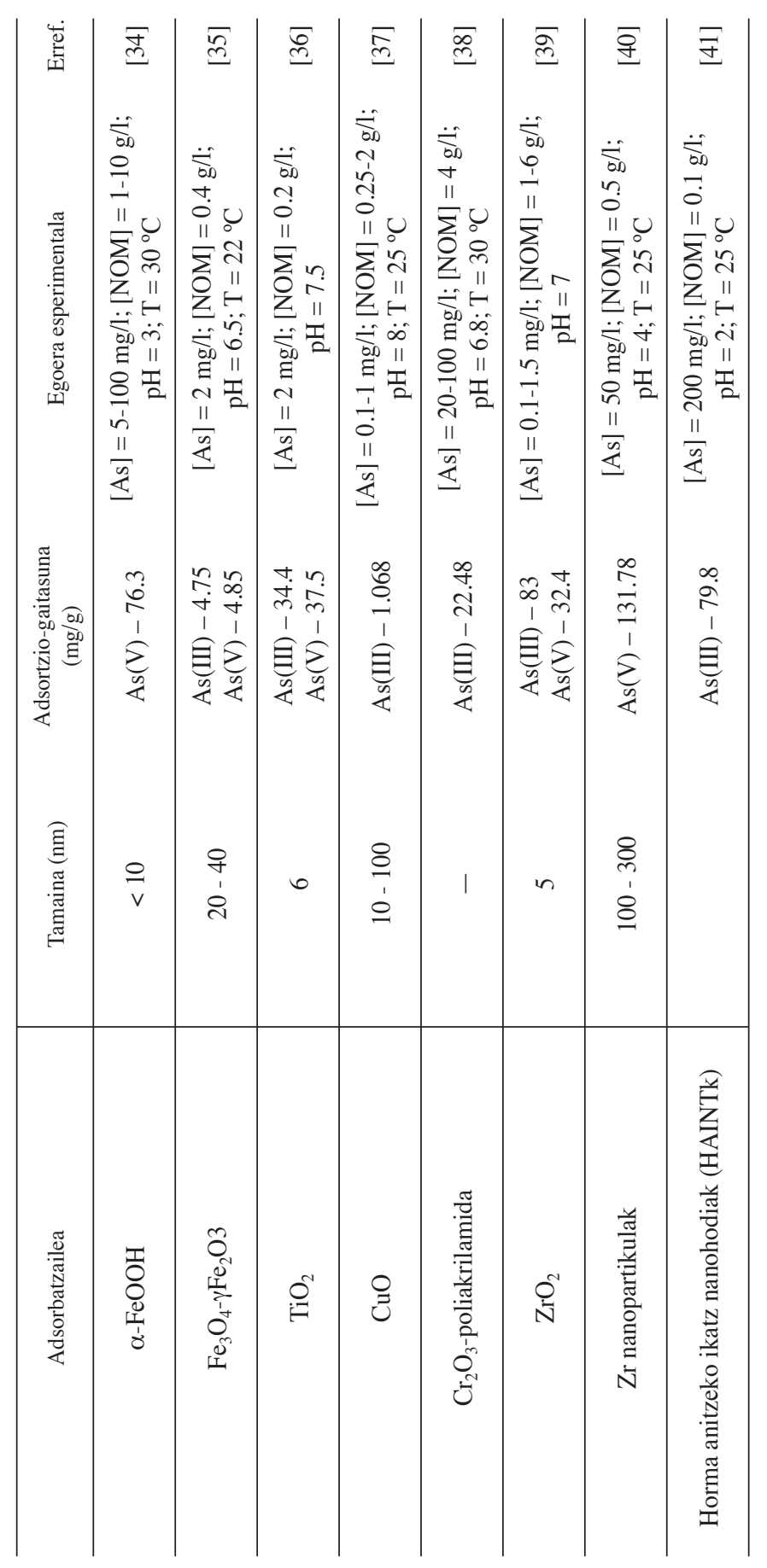

EKAIA, 29 (2016) 
Lehenago esan den moduan, material mikrometrikoetatik nanometrikoetara igarotzeak gaitasun handiagoa ematen dio toxikoen eliminazio prozesuari, baina zoritxarrez honekin batera hainbat eragozpen ere sortzen dira. Nanomaterialetan gainazal-energia handitzeak ezegonkortasuna dakar. Horren ondorioz, Van der Waals indarrak edo antzeko maila duten elkarrekintzak gertatzen dira, eta ondorioz, NOMak multzokatzeko joera azaltzen da. Multzokatze horrek metalen berreskurapen-gaitasunaren galera partziala eragiten du, eta kasu batzuetan erabatekoa. Era berean, nanopartikulek metalen berreskurapen prozesuan arazoak izan ditzakete eta, horregatik, kasu askotan tamaina handiagoa duten euskarri porotsuak erabiltzen dira, efizientzia handitzearren. Bada beste berreskurapen-teknika bat, nanosistemaren gainazala arriskuan jartzen ez duena eta nanopartikula magnetikoak erabiltzen dituena. Nanopatikula hauek berreskuratzea oso erraza da, eremu magnetiko baten bidez erakar baitaitezke, inongo korronte elektrikorik erabili gabe. Horrek merkatu egiten du prozesua. Hurrengo taulan artsenikoa berreskuratzeko erabili izan diren material desberdinak ikus daitezke:

Aztertutako nanomaterialen artean zero balentzia duten burdinazko nanopartikulak (ZBBn) nabarmentzen dira. Hauen aplikazioa, eskala handian egiten hasi dira [42-43]. Nanopartikulak aire zein urarekin kontaktuan jartzean, burdin oxido edo hidroxidozko geruza bat eratzen da haien gainazalean. Geruza hori da metal astunen berreskurapen-eraginkortasun altuaren erantzule. Izan ere, metalak bertan dauden oxigeno zein hidroxido taldeekin lotuko dira, disoluziotik murgilduta egotetik adsorbatzailera lotuta egotera pasatuz. Artsenikoaren kasuan ZBBn nanopartikulek As(III)-ren oxidazioa eragin dezakete [44]. Honekin batera, burdin oxido nanopartikulak ere (magnetita $-\mathrm{Fe}_{3} \mathrm{O}_{4}-$ eta maghemita $-\gamma-\mathrm{Fe}_{2} \mathrm{O}_{3}-$ ), adsortzio gaitasun handia dutenez, gailendu egiten dira.

Kasu honetan, nanopartikulen gainazala ur molekulen adsortzioa dela eta, hidroxilo taldeez estaltzen da eta medio azidoetan $\mathrm{FeOH}^{+}$edo $\mathrm{FeOH}_{2}{ }^{+}$ bezalako taldeak sortzen dira. Modu honetan, nanopartikulen gainazala positiboki kargatuta geratzen da eta elkarrekintza elektrostatikoen bidez artseniato motako anioiak bereganatzen dituzte. Gainera, gaur egun, nanopartikulak ekoizteko prozedurak garatu dira eta, adibidez, koprezitazio edo solbotermal tekniken bidez maghemita nanopartikulak sintetiza daitezke modu erraz eta merkean.

Material hauek abantaila nagusi modura dute erauzketa metodo magnetikoen burutu ahal izatea. Nanoadsorbazio prozesuan nanopartikulak artsenikoz kutsatutako disoluzioarekin kontaktuan jartzen dira. Horrela, artsenikoa selektiboki izaera magnetikoa aurkeztuko duten nanopartikulei atxikita geratuko da. Gero, artsenikoa gainazalean adsorbitu duten nanopartikulak erakarriko dituen eremu magnetiko indartsu baten eraginpean jarriko da sistema. Amaitzeko, bereizketa dekantazio bidez egingo da. 5. Irudian ikus 
daiteke azaldu berri den berreskurapen prozesuaren eskema, magnetoforesi izena duena.

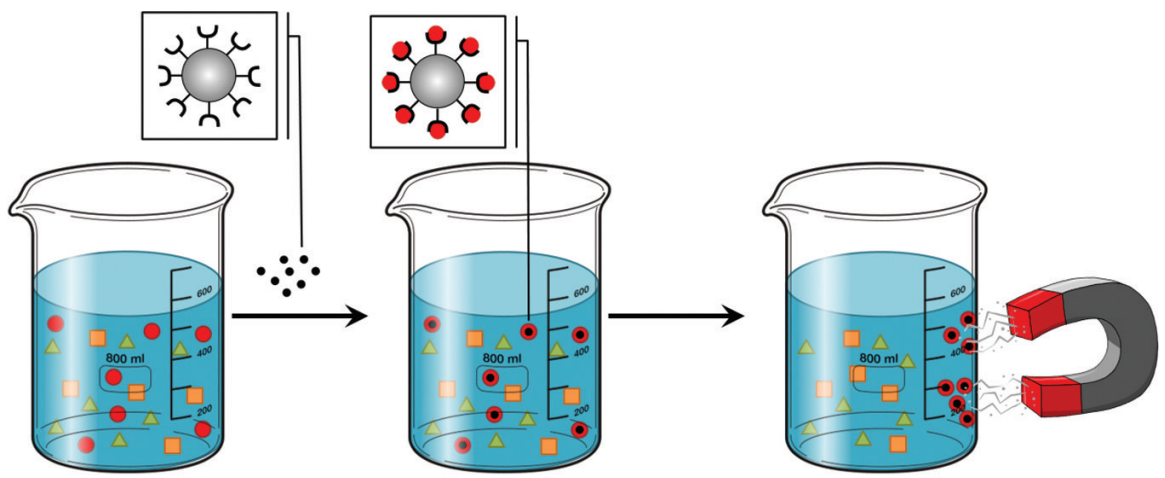

5. irudia. Nanoabsorbatzaileen bidezko magnetoforesi prozesuaren eskema.

Sistema hau erabili ahal izateko, ezinbestez optimizatu behar dira pH-a, nanoadsorbatzailearen kontzentrazioa, nanoadsorbatzaileak disoluzioarekin kontaktuan dauden denbora, artsenikoaren hasierako kontzentrazioa edo sistemari egokituko zaion eremu magnetikoaren intentsitatea bezalako parametroak. Aldagai guztiak finkatu ondoren, merkea, erraza eta maila desberdinetan erabil litekeen sistema bat izango litzateke. Bestelako bereizketa prozesuekin alderatuz, azpimarratzekoak dira sistema honek dituen berreskurapenerako hautakortasun, eraginkortasun eta azkartasun handiak. Gainera, eremu magnetiko iraunkor baten erabilerak elektrizitatearen beharra alde batera uzten du, eta horrek erraztu egiten du prozesua.

Orain arte ikusitakoari erreparatuz, burdin oxidozko nanopartikulen erabilera da artsenikoa berreskuratzeko biderik egokiena. Izan ere, adsortzio-azalera eta artsenikoarekiko afinitate handia dute nanopartikula hauek. Ingurumen-arazoekiko eta oxidazioarekiko erresistentzia altua dutenez, «in situ» aplikazioa ahalbidetzen dute. Honek esan nahi du erreka edo ibai baten tratamendua zuzenean egin daitekeela aurretratamendurik egin gabe; burdin oxido nanopartikulak ibaira edo errekara zuzenean isuri daitezke. Bertako urarekin kontaktuan egon ondoren artseniko katioiak nanosisteman atxikituak geratuko dira. Gero, eremu magnetiko indartsu bat erabiliz nanopartikulak erraz berreskuratuko dira, kutsatutako ura garbi utziz.

Esanak esan, sistemaren eraginkortasuna handitzeko nanopartikulak eraldatu egin behar dira. Horretarako silizio dioxidoz estaltzen dira, nanopartikulen aglomerazioa ekiditeko. Gero funtzionalizazioa egiten da. Alegia, ondo finkatzen da talde funtzionala, nanopartikularen gainazalean metala modu azkarragoan eta eraginkorragoan harrapatuko duena. 
Nanopartikulez osatutako nanosistema hau, baliagarria da artsenikoz kutsatutako ura, airea eta zorua tratatzeko. Gainera, elektrizitatea ez erabiltzeak eta duen sinpletasunak metodoa asko merkatzen du. Bestalde, kimika berdearen ideiekin bat egiten duen prestaketa eta karakterizazioa bideratu daiteke eta ahalbidetu lezake baldintza optimoetan $10 \mu \mathrm{g}$ artseniko/L-ko kontzentrazio mugatik azpiko urak lortzea. Hortaz, esan daiteke artsenikoaren berreskurapenerako metodorik eraginkorrenetarikoen artean dagoela.

\section{ONDORIOAK}

Gaur egun metal astunek eragiten duten kutsadura arazo oso larria da, batez ere hauek gizakiongan eta ingurumen-sistemetan eragiten ari diren kalteengatik. Euren propietate kimiko eta fisikoak medio, adsorbatzaile nanometrikoak dira, ingurumen erremediaziorako materialik egokienetakoak. Gainera, nanomaterialen funtzionalizazio errazak aukera eskaintzen du berreskurapen prozesuetarako hautakortasun handiko materialak sortzeko. Honekin batera, nanopartikula magnetikoen erabilerari esker magnetoforesia erabil daiteke; teknika hau gaur egungo metodoak baino egokiagoa da. Sistema tradizionalekin alderatuz, prozesu honek dituen adsortzio gaitasun handia eta erauzketa-azkartasuna azpimarratu daitezke. Oraindik sistemaren ingurumen-aplikazioaren prozesuaren inguruan lanean gabiltza; hori dela eta, ezinbestekoa da nanomaterialen berreraikitze prozesuen eta desortzio-mekanismoen ikerketa lanetan jarraitzea.

\section{ESKER ONAK}

Artikulu hau gauzatzeko lagundu eta bultzatu gaituzten kide eta erakunde guztiei eskerrak ematea gustatuko litzaiguke. Lehenik eta behin, Jose Ignacio Ruiz de Larramendiri eskerrak eman nahi dizkiogu lan urte hauetan zehar emandako laguntza eta aholkuengatik. Era berean Imanol Landari, emandako laguntza, konfiantza eta artikulu hau prestatzeko gomendioak eskertu nahi dizkiogu. Amaitzeko, Fernando Sarrionandiari ere eskerrak eman nahi dizkiogu artseniatoaren sorrera prozesu geologikoekin eskainitako laguntzagatik.

Lan hau Eusko Jaurlaritzaren (IT-570-13 proiektua) eta Ministerio de Educación y Ciencia-ren (MAT2013-41128-R proiektua) diru-laguntzei esker burutu da. 
Nanoteknologia: artsenikoaren erauzketarako bide berria

\section{BIBLIOGRAFIA}

[1] MANDAL, B.K. eta SUZUKI, K T. 2002. "Arsenic round the world: a review». Talanta, 58, 201-235.

[2] MATSCHULlAT, J. 2000. «Arsenic in the geosphere- a review». The Science of the Total Environment, 249, 297-312.

[3] SMEDLEY, P.L. eta KINNINBURGH, D.G. 2002. «A review of the source, behaviour and distribution of arsenic in natural waters». Applied Geochemistry, 17, 517-568

[4] COTTON, F.A. eta WILKINSON, G. 2008. Química inorgánica abanzada. Limusa, Mexico.

[5] HENKE, K. 2009. Arsenic: Environmental Chemistry, Health Threats and Waste Tratment. Wiley, Chichester.

[6] BIA, G., BORGNINO, L., GAIERO, D. eta GARCIA, M.G. 2015. «Arsenin-bearing phases in South Andean volcanic ashes: Implications fot As mobility in aquatic environments». Chemical Geology, 393-394, 26-35.

[7] NG, J. C. 2005. «Environmental Contaminatioin of Arsenic and its toxicological Impact on Humans». Environmental Chemistry, 2, 146-160.

[8] SMITH, A.H., LINGAS, E.L. eta RAHMAN, M. 2000. «Contamination of drinking-water by arsenic in Bangladesh: a public health emergency». Bulletin of the World health Organization, 78 (9), 1093-1103.

[9] Aque fundazioa. Eskuragarri hemen: http://www.fundacionaquae.org/blog/ el-poder-de-lo-enano

[10] United States Environmental Protection Agency, 2015 (http://www.epa.gov/).

[11] World Health Organization, 2010. Exposure to arsenic: a major public health concern. WHO Document Production Services, Geneva.

[12] ALONSO, J.A., PÉREZ, A.I.A., PAYÁN, A.A., CORTA, B.G., VALVO, E.G., GARCÍA, V.G., MENDIZÁBAL, R.I., URIBE, I. O., MENDÍA, A.M.U. eta FUENTE, J.V. 1999. Los residuos peligrosos. Caracterización, tratamiento y gestión. Sintesis, Madrid.

[13] FU, F. eta WANG, Q. 2001. «Removal of heavy ions from wastewaters: A review». Journal of Environmental Management, 92, 407-418.

[14] SOGAARD, E. 2014. Chemistry of Advanced Environmental Purification Processes of Water. Fundamentals and Applications. Elsevier, Amsterdam.

[15] MOHAN, D. eta PITTMAN JR., C.U. 2007. «Arsenic removal from water/ wastewater using adsorbents- A critical review». Journal of Hazardous Materials, 142, 1-53.

[16] ROCO, M.C. 2002. «Government nanotechnology funding:An international outlook». Journal of The Minerals, Metals \& Materials Society, 54, 22-23.

[17] GLEITER, H. 1992. «Nanostructured Materials», Advanced Materials, 4, 474-481.

[18] HENGLEIN, A. 1989. «Small-particle research: physicochemical properties of extremely small colloidal metal and semiconductor particles». Chemical Reviews, 89, 1861-1873. 
[19] WELLER, H. 2003. «Colloidal Semiconductor Q-Particles: Chemistry in the Transition Region Between Solid State and Molecules». Angewandte Chemie International Edition, 32, 41-53.

[20] STARA, J.V., PARK, D.G., LAGADIE, I. eta KLABUNDE, K.J. 1996. «Nanoscale Metal Oxide Particles/Clusters as Chemical Reagents. Unique Surface Chemistry on Magnesium Oxide As Pressure Dependence» Chemistry of Materials, 8, 1904-1912

[21] STARA, J.V. eta KLABUNDE, K.J. 1996. «Nanoscale Metal Oxide Partivles/Clusters as Chemical Reagents. Adsorption of Hydrogen Halides, Nitric Oxide, and sulfur Trioxide onMagnesium Oxide nanocrystals ans Compared with microcrystals». Chemistry of Materials, 8, 1913-1918.

[22] SUN, Y. eta XIA, Y. 2002. «Shape-Controlled synthesis of Gold and silver nanoparticules. Science, 298, 2176-2179.

[23] KOPER, O.B. eta KLABUNDE, K.J. 1997. «Destructive Adsorption of Chlorinated Hydrocarbons on ultrafine (Nanoscale) Particles of Calcium oxide. 3. Chloroform, Trichloroethene, and Tetrachloroethene». Chemistry of Materials, 9 , 2481-2485.

[24] TANBOONCHUY , V., HSU , J.-C., GRISDANURAK , N. eta LIAO, C.-H. 2011. «Impact of selected solution factors on arsenate and arsenite removal by nanoiron particles». Environmental Science and Pollution Research, 18, 857-864.

[25] ZHU, H., JIA, Y., WU, X. eta WANG, H. 2009. «Removal of arsenic from water by supported nano zero-valent iron on activated carbón». Journal of Hazardous Materials, 172, 1591-1596.

[26] GUPTA, A., YUNUS, M. eta SANKARARAMAKRISHNAN, N. 2012. «Zerovalent iron encapsulated chitosan nanospheres - a novel adsorbent for the removal of total inorganic arsenic from aqueous systems». Chemosphere, 86, $150-155$.

[27] LIN, S., LU, D. eta LIU, Z. 2012. «Removal of arsenic contaminants with magnetic $\gamma-\mathrm{Fe}_{2} \mathrm{O}_{3}$ nanoparticles». Chemical Engineering Journal, 211-212, 46-52.

[28] PARK, H., MYUNG, N.V., JUNG, H. eta CHOI, H. 2009. «As(V) remediation using electrochemically synthesized maghemite nanoparticles». Journal of Nanoparticle Research, 11, 1981-1989.

[29] TURK, T., ALP, I. eta DEVECI, H. 2010. «Adsorption of As(V) from water using nanomagnetite». Journal of environmental Chemical Engineering, 136, 399-404.

[30] ZHANG, F., LAN, J., ZHAO, Z., YANG, Y., TAN, R. eta SONG, W. 2012. «Removal of heavy metal ions from aqueous solution using $\mathrm{Fe}_{3} \mathrm{O}_{4}-\mathrm{SiO}_{2-}$ poly(1,2-diaminobenzene) core-shell sub-micron particles». Journal of Colloid and Interface Science, 387, 205-212.

[31] KARIMI, M.A., MOHADESI, A., HATEFI-MEHRJARDI, A., MOHAMMADI, S.Z., YARAHMADI, J. eta KHAYRKHAH, A. 2014. «Separation/ Preconcentration and Speciation Analysis of Trace Amounts of Arsenate and Arsenite in Water Samples Using Modified Magnetite Nanoparticles and Molybdenum Blue Method». Journal of Chemistry, 2014, 9 orrialde. 
Nanoteknologia: artsenikoaren erauzketarako bide berria

[32] MORILlO, D., UHEIDA, A., PEREZ, G., MUHAMMED, M. eta VALIENTE, M. 2015. «Arsenate removal with 3-mercaptopropanoic acidcoated superparamagnetic iron oxide nanoparticles». Journal of Colloid and Interface Science, 438, 227-234.

[33] TÜRK , T. eta ALP, I. 2014. «Arsenic removal from aqueous solutions with Fe-hydrotalcite supported magnetite nanoparticle». Journal of Industrial and Engineering Chemistry, 20, 732-738.

[34] GHOSH, M., POINERN, G., ISSA, T. eta SINGH, P. 2012. «Arsenic adsorption on goethite nanoparticles produced through hydrazine sulfate assisted synthesis method». Korean Journal of Chemical Engineering, 29(1), 95-102.

[35] CHOWDHURY, S.R., YANFUL, E. eta PRATT, A. 2010. «Arsenic removal from aqueous solutions by mixed magnetite-maghemite nanoparticles». Environmental Earth Sciences, 64, 411-423.

[36] PENA, M.E., KORFIATIS, G.P., PATEL, M., LIPPINCOTT, L. eta MENG, X. 2005. «Adsorption of As(V) and As(III) by nanocrystalline titanium dioxide». Water Research, 39, 2327-2337.

[37] GOSWAMI, A., RAULB, P.K. eta PURKAITA, M.K. 2012. «Arsenic adsorption using copper oxide (II) nanoparticles». Chemical Engineering Research and Design, 90(9), 1387-1396.

[38] RAHMAN, N. eta HASEEN, U. 2015. «Development of polyacrylamide chromium oxide as a new sorbent for solid phase extraction of As(III) from food and environmental water samples». RSC Advances, 5, 7311-7323.

[39] CUI, H., QI, L., GAO, S. eta SHANG, J. 2012. «Strong adsorption of arsenic species by amorphous zirconium oxide nanoparticles». Journal of Industrial and Engineering Chemistry, 18, 1418-1427.

[40] JINSONG, H., MATSUURA, T. eta CHEN, J.P. 2014. «A novel Zr-based nanoparticle-embedded PSF blend hollow fiber membrane for treatment of arsenate contaminated water: Material development, adsorption and filtration studies, and characterization». Journal of Membrane Science, 452, 433-445.

[41] TAVAKKOLI, N., HABIBOLLAHI, S. eta TEHRANI, S. A. 2014. «Separation and preconcentration of Arsenic(III) ions from aqueous media by adsorption on MWCNTs». Arabian Journal of Chemistry (prentsan) doi:10.1016/j.arabjc.2014.04.007

[42] TANG, S.C.N. eta LO, I.M.C. 2013. «Magnetic nanoparticles: essential factors for sustainable environmental applications». Water Research, 47, 2613-2632.

[43] MUELLER, N.C., BRAUN, J., BRUNS, J., CERNÍK, M., RISSING, P., RICKERBY, D. eta NOWACK, B. 2012. "Application of nanoscale zero valent iron (NZVI) for groundwater remediation in Europe». Environmental Science and Pollution Research Journal, 19, 550-558.

[44] YAN, W., RAMOS, M.A.V. , KOEL, B.E. eta ZHANG, W.-X. 2012. «As(III) sequestration by iron nanoparticles: study of solid-phase redox transformations with X-ray photoelectron spectroscopy». The Journal of Physical Chemistry C, 116, 5303-5311. 